(C) 1982. The Genetical Society of Great Britain

\title{
RESTRICTION ENDONUCLEASE ANALYSIS OF MITOCHONDRIAL DNA FROM SUGARBEET WITH NORMAL AND MALE-STERILE CYTOPLASMS
}

\author{
ANDREW POWLING \\ John Innes Institute, Colney Lane, Norwich, NR4 TUH, U.K.
}

Received 30.iii.82

\section{INTRODUCTION}

MrTOCHONDRIA from sugarbeet (Beta vulgaris L.) contain small ( 1.5 to $1 \cdot 3$ kilobase pairs, $\mathrm{kb}$ ) circular DNA molecules (Powling, 1981) in addition to their main mitochondrial chromosome. Normal and cytoplasmic male sterile (cms) types contain different combinations of these small molecules. The main (high molecular weight) mitochondrial DNA (mtDNA) of malefertile and cms sugarbeet has now been investigated using restriction endonuclease digestion and electrophoretic separation of the fragments. This work follows the approach of other studies which have shown differences between the mtDNAs of normal and cms types of maize and sorghum (Pring and Levings, 1978; Pring et al, 1979).

\section{MATERIALS AND METHODS}

The lines and varieties of sugarbeet used in this work are listed in table 1. All the male-fertile lines are maintainer lines (0-types), i.e., they do not contain nuclear restorer genes and, when crossed to cms lines, allow the cms character to be maintained in the offspring.

Mitochondrial DNA was isolated as previously described (Powling, 1981). Restriction endonucleases BamHI and SalGI were obtained from Bethesda Research Laboratories. RNase was from Boehringer. Restriction digestions were performed in the buffers recommended by the enzyme supplier. Enzymes (routinely 8 to 10 units per digest) were usually divided into two equal aliquots, the second being added $3 \mathrm{hr}$ after the first. Total digestion times were 6 to $8 \mathrm{hr}$ at $37^{\circ} \mathrm{C}$. Before electrophoresis RNase (boiled for $10 \mathrm{~min}$ before use) was added for $10 \mathrm{~min}$ at room temperature.

Agarose (Sigma) gels were prepared in a buffer containing $40 \mathrm{mM}$ tris- $\mathrm{HCl}, 5 \mathrm{mM}$ sodium acetate, $1 \mathrm{mM}$ EDTA, $p \mathrm{H} \mathrm{7.9.} \mathrm{Sal} \mathrm{GI} \mathrm{digests} \mathrm{were}$ separated on horizontal 0.4 per cent agarose gels run at $1 \mathrm{~mA} / \mathrm{cm}$ for $24 \mathrm{hr}$ at room temperature. BamHI digests were separated on vertical 0.8 per cent agarose gels run at $1 \mathrm{~mA} / \mathrm{cm}$ for $20 \mathrm{hr}$ at $4^{\circ} \mathrm{C}$. Gels were stained with ethidium bromide, illuminated with UV light $(254 \mathrm{~nm})$ and photographed with Polaroid film.

\section{RESUlts}

Samples of total mitochondrial DNA from a pair of sugarbeet lines nearly isogenic except for the $\mathrm{cms} / \mathrm{male}$-fertile character were digested with $\mathrm{BamHI}$. The resulting fragments were separated by gel electrophoresis (fig. 1). Lane 1 shows the male-fertile line, and lane 2 shows the cms line. 
TABLE 1

Classification of the sugarbeet lines and varieties tested, their sources and the types (see text) of the SalGI digestion products of their mtDNA

$\begin{array}{ccc}\begin{array}{c}\text { Source, and } \\ \text { line or variety } \\ \text { Plant Breeding } \\ \text { Institute, Cambridge }\end{array} & \begin{array}{c}\text { Cytoplasm: male } \\ \text { fertile/sterile }\end{array} & \begin{array}{c}\text { Type of SalGI digestion } \\ \text { products of mtDNA }\end{array} \\ \text { SA3 } & \text { F } & \\ \text { SA8 } & \text { F } & 1 \\ \text { SD1 } & \text { F } & 1 \\ \text { SW3 } & \text { F } & 1 \\ \text { RA18 } & \text { S } & 2 \\ \text { RD1 } & \text { S } & 2 \\ \text { RU7 } & \text { S } & 2 \\ \text { RW10 } & \text { S } & 2 \\ \text { RX1 } & \text { S } & 2 \\ \text { Anglo-Maribo Ltd. } & & \\ \text { SRA5 } & \text { F } & 1 \\ \text { SRA6 } & \text { S } & 2 \\ \text { SRA7 } & \text { F } & 1 \\ \text { SRA8 } & \text { S } & 2 \\ \text { Amazon } & \text { S } & 2 \\ \text { Amono } & \text { S } & 2 \\ \text { Bush Johnsons Ltd. } & & \\ \text { I 13M4 } & \text { F } & 1 \\ \text { 01 I 13M4 } & \text { S } & 2 \\ \text { Hilleshog Ltd. } & & \\ \text { Salohill } & \text { S } & 2 \\ \text { Vytomo } & \text { S } & \end{array}$

It can be seen that these lines give distinctly different patterns of fragments. Mitochondrial DNAs from two other pairs of nearly isogenic cms/malefertile lines from different sources were also digested with BamHI (not shown). They were found to give patterns very similar to those in fig. 1, indicating that the difference between cms and fertile lines is general. However, digestion with $\mathrm{BamHI}$ gives more fragments than can be distinguished easily after electrophoresis. Therefore further digestions were performed using SalGI, which was found to cut the DNA into fewer fragments.

Fig. 2 shows the distribution of fragments obtained when mtDNAs from these same six lines were digested with SalGI. Again all the male-fertile lines (lanes 2, 4 and 6) give a pattern, here called type 1, clearly distinguishable from that obtained from the cms lines, type 2, (lanes 3,5 and 7). Mitochondrial DNAs from various other lines and varieties were digested with SalGI and the products analysed by electrophoresis. It was found that all male-fertile lines gave the type 1 pattern, and all the cms lines gave the type 2 pattern. Table 1 lists the lines and varieties tested and their fragment pattern types. The small circular mtDNA species described previously (Powling, 1981) were not seen in the present work since, even if uncut by the enzymes used, they would have migrated beyond the zone of resolution on the gels. 


\section{Plate III}

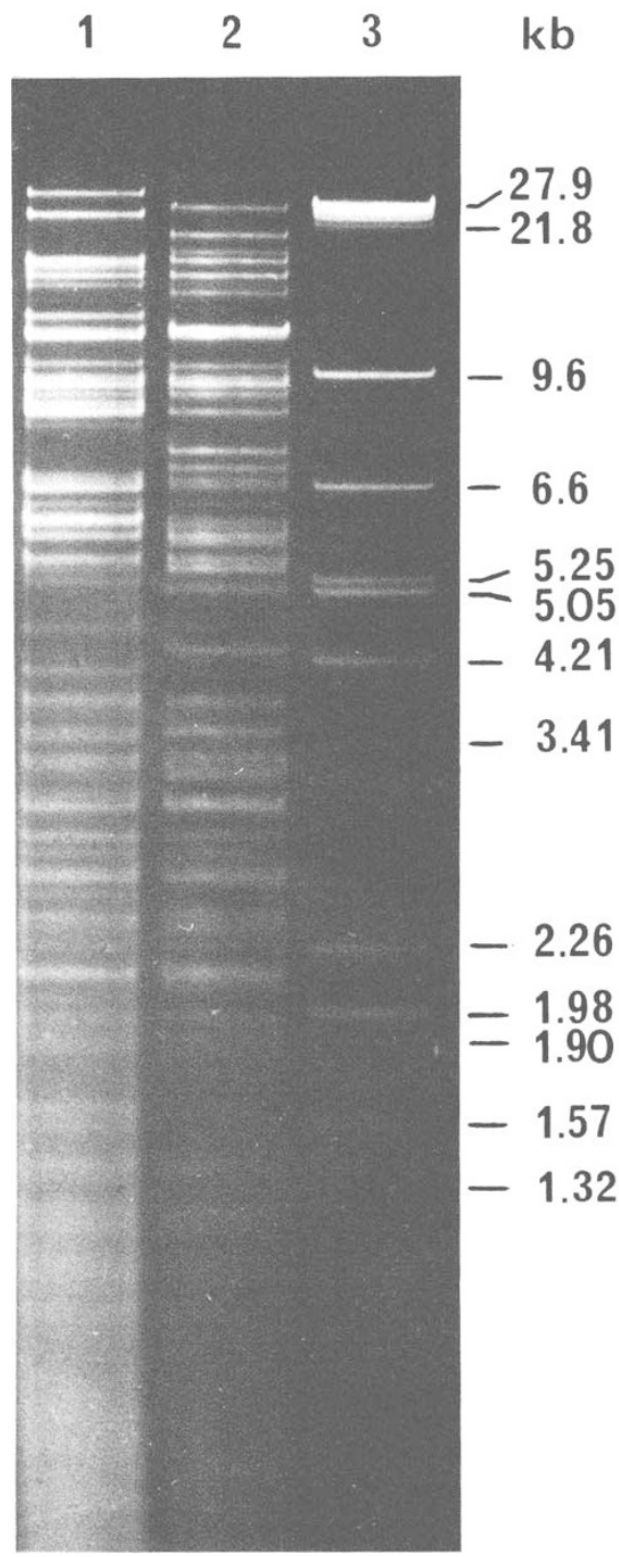

FIG. 1,-BamH1 digests of sugarbeet mtDNAs analysed by electrophoresis on a 0.8 per cent agarose gel. Lane 1: I 13M4 (male-fertile). Lane 2=01 I 13M4 (cms). Lane $3=$ Marker fragments (bacteriophage $\lambda$ DNA digested with BamHI and HindIII) with sizes in kilobase pairs. 
Plate IV

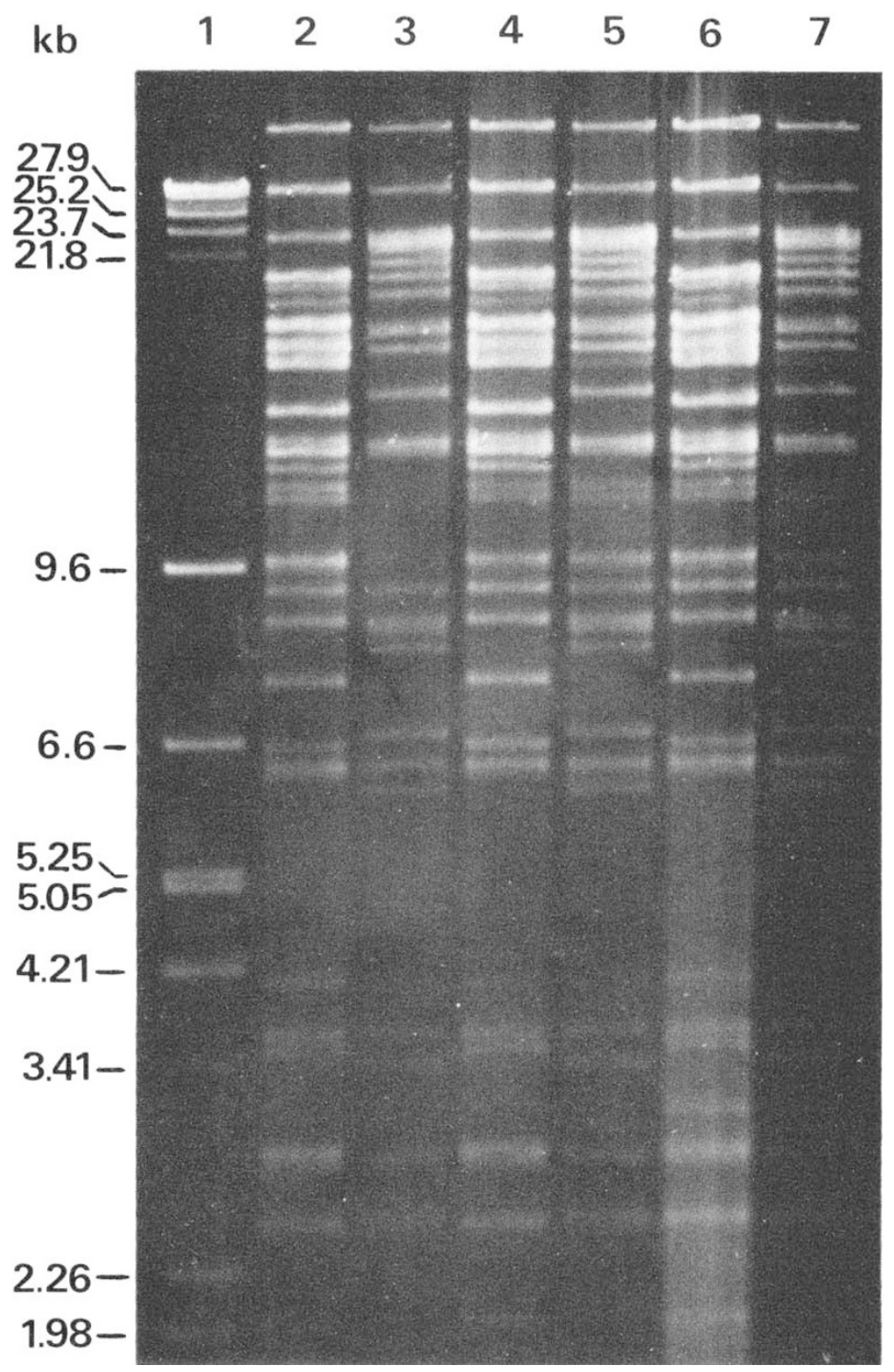

FIG. 2.-SalGI digests of sugarbeet mtDNAs analysed by electrophoresis on a 0.4 per cent agarose gel. Lane $1=$ Marker fragments (bacteriophage $\lambda$ DNA digested with BamHI and HindIII) with sizes in kilobase pairs. Lane $2=\mathrm{SD} 1$ (male-fertile). Lane $3=\mathrm{RD} 1$ (cms). Lane $4=$ SRA5 (male-fertile). Lane 5= SRA6 (cms). Lane 6=1 13M4 (malefertile). Lane $7=01$ I 13M4 (cms). 
Densitometer scans of negatives of the gels were made to allow estimation of the amount of DNA in each band. Areas under individual peaks on a trace where compared with the sizes (in kilobase pairs) of the fragments forming the peaks. It was found that the majority of bands contained equal numbers of DNA fragments. It is assumed that the fragments forming these bands consist of sequences present once per mitochondrial genome, and the bands are referred to as single bands. Other bands contained two or three times as many DNA fragments as the majority. These bands could contain two or three different sequences each present in the same numbers as the fragments forming the single bands, or two or three times the normal number of copies of a single sequence. Some bands (those appearing noticeably faint in fig. 2) clearly contained fewer DNA fragments than the single bands. These faint bands were of the same molecular weight in both male-fertile and cms lines. It is possible that these fragments originate from molecule(s) which are present in lower numbers in mitochondria than the molecule(s) forming the rest of the mitochondrial genome.

One minor difference was observed between the male-fertile lines; three (SA8, SW3 and I13M4) were found to have a fragment of $3.15 \mathrm{~kb}$ not present in the other fertile lines tested.

Estimates of the size of the sugarbeet mitochondrial genome were made by comparing the area under a peak of a representative single band of known molecular weight with the total area under all the peaks on the same densitometer trace. Estimates were made using several single bands on a trace, the results averaged and standard errors calculated. From a trace of a male-fertile line (SW3) a value of $379 \pm 39$ was obtained (nine single peaks used, average separation $4 \cdot 1 \mathrm{~kb}$ ). The same procedure was followed for two cms lines which differed in the intensity of their faint bands-Vytomo, in which the faint bands were very weak, and Salohill, in which the faint bands were rather more distinct. The estimates were $375 \pm 24$ for Vytomo and $412 \pm 38$ for Salohill (eight single peaks used, average separation $4.4 \mathrm{~kb}$ ). Clearly a method other than restriction endonuclease digestion must be used if more precise estimates are to be obtained.

\section{Discussion}

The results presented here show that there are (at least) two different types of mtDNA found in sugarbeet. One type is associated with normal male-fertility and the other with cms. The differences in the restriction digests are in addition to the differences in the combinations of small circular mtDNA species previously observed (Powling, 1981). Both provide a way of distinguishing between male-fertile and male-sterile cytoplasms. It might have been expected that the cms lines tested would have similar mtDNAs, since these lines were all derived from American cms material (K. Öhlund, personal communication), which in turn was derived from the variety US1 (Owen, 1945; Theurer and Mumford, 1976). The similarity in the mtDNAs from the male-fertile lines tested may indicate that these lines also have been derived relatively recently from a common cytoplasm.

The estimates of the sugarbeet mitochondrial genome size obtained from this work (very approximately in the region of $400 \mathrm{~kb}=$ 265 Megadaltons) may be compared with estimates of the sizes of other plant mitochondrial genomes obtained by digestion with SalGI. Lebacq 
and Vedel (1981) found mitochondrial genome sizes of six Brassica species to range from $108.5 \mathrm{Md}$ to $138.5 \mathrm{Md}$, Ward et al. (1981) found values of $227 \mathrm{Md}$ for watermelon, $228 \mathrm{Md}$ for pea, $412 \mathrm{Md}$ for maize and $528 \mathrm{Md}$ for zucchini (assuming multiple bands to contain multiple sequences). Muskmelon and cucumber mtDNAs were too big to be determined by SalGI digestion and estimates of $1600 \mathrm{Md}$ and $1000 \mathrm{Md}$ respectively were obtained by renaturation kinetics (Ward et al. 1981). Therefore the mitochondrial genome of sugarbeet is well within the range of other plant mtDNA sizes.

Intraspecific heterogeneity associated with $\mathrm{cms}$ has previously been found in maize and sorghum. The three cms types of maize (cmsT, cmsS and $\mathrm{cmsC}$ ) and male-fertile maize all have their own characteristic mtDNA digest patterns (Pring and Levings, 1978). Sorghum has been reported to contain at least six different cms types on the basis of restriction digest patterns (Pring et al., 1979). Differences in the proteins synthesised by mitochondria from different cms types have been demonstrated for both maize and sorghum (Forde and Leaver, 1980; Dixon and Leaver, 1982). These findings are among the best evidence that the genetic determinants controlling cms in these species are located in the mitochondria (review: Leaver and Gray, 1982).

The results presented here suggest, but by no means prove, that in sugarbeet the mtDNA may carry the genetic determinant(s) of cms. Thus, it may be possible that the mechanism of cms in sugarbeet (a dicotyledon) is similar to the mechanisms of $\mathrm{cms}$ in maize and sorghum (monocotyledons).

Acknowledgments.-I thank Professor D. R. Davies and Dr T. H. N. Ellis for valuable discussions during the course of this work, which was supported by a John Innes Charity Fellowship.

\section{REFERENCES}

DIXON, L. K., AND LEAVER, C. J. 1982. Mitochondrial gene expression and cytoplasmic male sterility in Sorghum. Plant Mol. Biol., 1 in the press.

FORDE, B. G., AND LEA VER, C. J. 1980. Nuclear and cytoplasmic genes controlling synthesis of variant mitochondrial polypeptides in male-sterile maize. Proc. Natl. Acad. Scí. U.S., 77, 418-422.

LEAVER, C. J., AND GRAY, M. W. 1982. Mitochondrial genome organisation and expression in higher plants. Ann. Rev. Pl. Physiol., 33, 373-402.

LEBACQ. P., AND VEDEL, F. 1981. Sal1 restriction enzyme analysis of chloroplast and mitochondrial DNAs in the genus Brassica. Pl. Sci. Letts., 23, 1-9.

OWEN, F. V. 1945. Cytoplasmically inherited male-sterility in sugarbeets. J. Ag. Res., 71, 423-440.

POWLING, A. 1981. Species of small DNA molecules found in mitochondria from sugarbeet with normal and male-sterile cytoplasms. Mol. Gen. Genet., 183, 82-84.

PRING, D. R., AND LEVINGS III, C. S. 1978. Heterogeneity of maize cytoplasmic genomes among male-sterile cytoplasms. Genetics, 89, 121-136.

PRING, D. R., LEVINGS III, C. S., AND CONDE, M. F. 1979. The organelle genomes of cytoplasmic male-sterile maize and sorghum. In Davies, D. R., and Hopwood, D. A. (eds.) The Plant Genome, The John Innes Charity, Norwich, U.K.

THEURER, J. C., AND MUMFORD, D. L. 1976. The effect of sterile cytoplasm on curly top disease resistance. J. Am. Soc. Sugar Beet Technol., 19, 45-48.

WARD, B. L., ANDERSON, R. S., AND BENDICH, A. J. 1981. The mitochondrial genome is large and variable in a family of plants (Cucurbitaceae). Cell, 25, 793-803. 